\title{
Color Change in the Gorgetal Scales of an Anole, Anolis amplisquamosus (Squamata: Dactyloidae)
}

Tom W. Brown ${ }^{1,2}$, John David Curlis ${ }^{1,3}$, George Lonsdale ${ }^{1,4}$, Cameron Thorpe ${ }^{1}$, and Alexander Hoad ${ }^{1}$

${ }^{1}$ Operation Wallacea, Hope House, Old Bolingbroke, Lincolnshire PE23 4EX, United Kingdom (browntb@outlook.com)

${ }^{2}$ Kanahau Utila Research and Conservation Facility, Isla de Utila, Honduras

${ }^{3}$ Department of Ecology and Evolutionary Biology, University of Michigan, Ann Arbor, Michigan, USA

${ }^{4}$ Cornwall College, Wildflower Lane, Trenance Gardens, Newquay, Cornwall, TR7 2LZ, United Kingdom

$\mathrm{T}^{\mathrm{s}}$ he genus Anolis is comprised of over 400 largely Neotropical lizards belonging to the family Dactyloidae (e.g., Uetz et al. 2018). Nicholson et al. (2012) most recently proposed the recognition of multiple anoline genera (sometimes considered subgenera or clades within the "crown clade" Anolis, e.g., Poe et al. 2017). Among these is the genus Norops, to which the species Anolis amplisquamosus was originally assigned (McCranie et al. 1992). This is an understudied species that occurs at intermediate elevations in the Sierra de Omoa in northwestern Honduras (McCranie and Köhler 2015) and is one of ten species assigned to the Anolis crassulus species group (Hofmann and Townsend 2017). The species is considered endemic to this region and is known only from the vicinity of its type locality in Parque Nacional El Cusuco (PNC), Cortes, Honduras. Currently, A. amplisquamosus is classified as Endangered on the IUCN Red List in recognition of its limited distribution and suggestions of a dramatic population decline (Mayer 2011; Townsend et al. 2006).

Although many morphological characters define species of anoles (e.g., Losos 2009), the most diagnostic method of identification is the coloration of dewlaps, a constituent of which is the color of gorgetal scales. As anoline species often occur sympatrically, dewlap color can play a key role in species recognition and intraspecific interactions (e.g., Macedonia and Stamps 1994). McCranie and Köhler (2015) noted that recording coloration in living specimens (especially the dewlaps of males) is extremely valuable in understanding one of the most important characters of any given species. They described the dewlap of $A$. amplisquamosus as being large and "chrome orange" in coloration, with 7-8 pale or dirty yel-
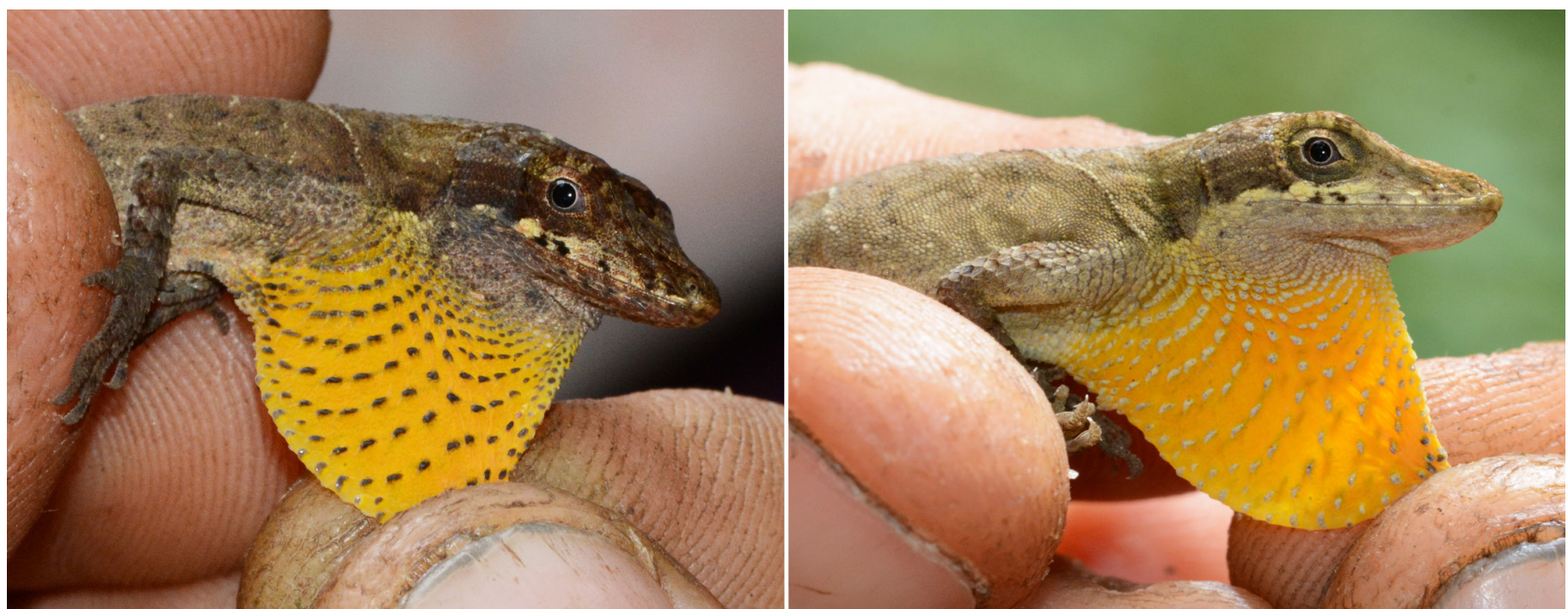

Fig. 1. An adult male Anolis amplisquamosus with black gorgetal scales immediately after capture (left); the same individual $\sim 10$ min later with white gorgetal scales. Photograph (C) John David Curlis. 
low horizontal gorgetal-sternal scale rows. Anoles are capable of dramatic color change, but gorgetal scale coloration is not generally considered variable (Savage 2002).

Herein we present an observation of chromatophoric regulation in A. amplisquamosus, reporting that this species has the ability to change the color of its gorgetal scales. Although the ability to regulate dorsal skin coloration is common among anoles, until now only Leenders and Watkins-Colwell (2003) have reported color change in the gorgetal scales of an anole dewlap - notably also involving a member of the $A$. crassalus species group.

While performing standardized herpetological research as part of Operation Wallacea's long-term biodiversity monitoring efforts in PNC, at $0943 \mathrm{~h}$ on 15 June 2018, we encountered numerous individuals of $A$. amplisquamosus active and basking on sunlit ferny vegetation along an old road leading from the PNC visitor's center to a private farm. This exact locality was reported to support abundant populations of this species in the 1980s and 1990s, yet these populations ostensibly have experienced severe declines in recent years (Townsend et al. 2006; McCranie and Köhler 2015). After capturing a male $(S V L=44.8 \mathrm{~mm}$; tail length $=102 \mathrm{~mm}$; mass $=2.4 \mathrm{~g}$ ), we manually extended the dewlap to confirm identification. We immediately observed that this individual's dewlap appeared noticeably different when compared to those previously described in the literature in having sharply contrasting black gorgetal scales on a typical "chrome orange" dewlap (Fig. 1). When checked again less than than $10 \mathrm{~min}$ later, the gorgetal scales had changed to a pale yellow (as previously described). Notably, the dorsal and lateral coloration of this individual also had transformed from a dark brown at the initial time of capture to a light gray/yellowish tan.

Although we cannot explain the basis for this change, it may be significant in the wider context of anoline biology in that the coloration of gorgetal scales may not always be a fixed descriptive or diagnostic feature - at least among members of the $A$. crassalus species group. Accordingly, we suggest that some anoles of the Norops clade might have the ability to regulate the color of their gorgetal scales in the same manner as they regulate dorsal and lateral scale color. Because the color of gorgetal scales is a character often used in species identification, understanding the mechanics and the purpose of such a change is crucial. Leenders and Watkins-Colwell (2003) suggested that darkening of the gorgetal scales could play a thermoregulatory role, and since $A$. amplisquamosus also inhabits mid-high elevation cloud-forest zones, metachrosis might help absorb solar radiation (e.g., Robinson 1983). As anoles are known to be "visually orientated" (e.g., Baeckens et al.
2016), gorgetal color change also could have implications for communication and display dynamics.

\section{Acknowledgements}

We sincerely thank Operation Wallacea for the financial and logistical support that enables us to perform biodiversity research in Cusuco National Park, Honduras. We also thank the staff, volunteers, and local guides, who make remote cloud forest exploration possible. Special thanks go to Dr. Tom Martin for his helpful reviews and comments regarding this observation. All field data collection was performed under valid biological research and collection permits issued to Operation Wallacea by the Instituto Nacional de Conservación y Desarrollo Forestal, Áreas Protegidas y Vida Silvestre (ICF), Tegucicalpa, Honduras.

\section{Literature Cited}

Baeckens, S., T. Driessens, and R. Van Damme. 2016. Intersexual chemo-sensation in a "visually-oriented" lizard, Anolis sagrei. PeerJ 4:e1874 (https://doi. org/10.7717/peerj.1874).

Hofmann, E.P. and J.H. Townsend. 2017. Origins and biogeography of the Anolis crassulus subgroup (Squamata: Dactyloidae) in the highlands of nuclear Central America. BMC Evolutionary Biology 17: 267.

Leenders, T.A. and G.J. Watkins-Colwell. 2003. Norops heteropholidotus (NCN). Dewlap coloration. Herpetological Review 34: 369.

Losos, J.B. 2009. Lizards in an Evolutionary Tree: Ecology and Adaptive Radiation of Anoles. University of California Press, Berkeley, California, USA.

Macedonia, J.M. and J.A. Stamps. 1994. Species recognition in Anolis grahami (Sauria, Iguanidae): evidence from responses to video playbacks of conspecific and heterospecific displays. Ethology 98: 246-264.

Mayer, G.C. 2011. Anolis amplisquamosus. The IUCN Red List of Threatened Species 2011: e.T178363A7531612 (http://www.iucnredlist.org/details/ full/178363/0).

McCranie, J.R. and G. Köhler. 2015. The anoles (Reptilia: Squamata: Dactyloidae: Anolis: Norops) of Honduras. Systematics, distribution, and conservation. Bulletin of the Museum of Comparative Zoology 161: 1-280.

McCranie, J.R., L.D. Wilson, and K.L. Williams. 1992. A new species of anole of the Norops crassulus group (Sauria: Polychridae) from northwestern Honduras. Caribbean Journal of Science 28: 208-215.

Nicholson, K.E., B.I. Crother, C. Guyer, and J.M. Savage. 2012. It is time for a new classification of anoles (Squamata: Dactyloidae). Zootaxa 3477: 1-108.

Poe, S., A. Nieto-Montes de Oca, O. Torres-Carvajal, K. de Quieroz, J.A. Velasco, B. Truett, L.N. Gray, M.J. Ryan, G. Köhler, F. Ayala-Varela, and I. Latella. 2017. A phylogenetic, biogeographic, and taxonomic study of all extant species of Anolis (Squamata; Iguanidae). Systematic Biology 66: 663-697.

Robinson, D.C. 1983. Sceloporus malachiticus (Lagartija espinosa, spiny lizard), pp. 421-422. In: D.H. Janzen (ed.), Costa Rican Natural History. University of Chicago Press, Chicago, Illinois, USA.

Savage, J.M. 2002. The Amphibians and Reptiles of Costa Rica: A Herpetofauna between Two Continents, between Two Seas. The University of Chicago Press, Chicago, Illinois, USA.

Townsend, J.H., L.D. Wilson, B.L. Talley, D.C. Fraser, T.L. Plenderleith, and S.M. Hughes. 2006. Additions to the herpetofauna of Parque Nacional El Cusuco, Honduras. Herpetological Bulletin 96: 29-39.

Uetz, P., J. Hallermann, and J. Hošek (eds.). 2018. The Reptile Database (http:// www.reptile-database.org). 